Cahiers $d u$ MONDE RUSSE

\section{Cahiers du monde russe}

Russie - Empire russe - Union soviétique et États indépendants

$48 / 4 \mid 2007$

Varia

\title{
Elizabeth Cheresh Allen, A Fallen Idol Is Still a God
}

\section{Michel Aucouturier}

\section{OpenEdition \\ Journals}

Édition électronique

URL : https://journals.openedition.org/monderusse/6063

DOI : 10.4000/monderusse.6063

ISSN : $1777-5388$

\section{Éditeur}

Éditions de l'EHESS

\section{Édition imprimée}

Date de publication : 2 décembre 2007

Pagination : 683-684

ISBN : 978-2-7132-2148-4

ISSN : $1252-6576$

\section{Référence électronique}

Michel Aucouturier, «Elizabeth Cheresh Allen, A Fallen Idol Is Still a God », Cahiers du monde russe [En ligne], 48/4 | 2007, mis en ligne le 16 juin 2009, consulté le 03 septembre 2022. URL : http:// journals.openedition.org/monderusse/6063; DOI : https://doi.org/10.4000/monderusse.6063

Ce document a été généré automatiquement le 3 septembre 2022

Tous droits réservés 


\title{
Elizabeth Cheresh Allen, A Fallen Idol Is Still a God
}

\author{
Michel Aucouturier
}

\section{RÉFÉRENCE}

\section{Elizabeth CHERESH ALLEN, A Fallen Idol Is Still a God. Lermontov and the Quandaries}

of Cultural Transition. Stanford, CA : Stanford University Press, 2007, 286 p.

1 Voici un livre qui a les défauts de ses qualités. Commençons par celles-ci, qui ne sont pas minces : la netteté de la thèse, la rigueur de la construction, la fermeté des analyses, la solidité d'une argumentation fondée sur une vaste information bibliographique, la qualité d'une écriture claire et concise.

2 La thèse est simple : Lermontov est un représentant accompli du postromantisme, celuici offrant le modèle parfait d'une époque de «transition culturelle ». En l'occurrence, il s'agit de la sortie du romantisme, dont l'idole, bien qu'abattue, reste pour notre poète un dieu : d'où le titre.

3 Les deux premiers chapitres définissent ce cadre conceptuel, d'abord en analysant la notion de "transition culturelle », puis en dressant un tableau du postromantisme en Europe occidentale et en Russie. Dans les six chapitres suivants, le schéma est appliqué successivement à six œuvres ou ensembles d'œuvres majeures de Lermontov : les poèmes «byroniens » des débuts, le grand poème Le Démon, commencé très tôt, mais auquel le poète a travaillé tout au long de sa brève carrière littéraire, son drame Le Bal masqué, son chef-d'œuvre, le roman Un héros de notre temps (auquel sont consacrés deux chapitres), et enfin la nouvelle Chtoss, qui fournit à l'auteur sa conclusion. À chacune de ces étapes, une analyse fouillée de l'œuvre permet selon l'auteur d'y retrouver les traits caractéristiques dégagés dans son deuxième chapitre d'introduction.

Ces analyses font scrupuleusement référence aux différentes interprétations avancées par les critiques antérieurs, surtout américains et russes (soviétiques en général), qui ont abordé l'œuvre du poète; elles sont menées avec fermeté, solidement et clairement 
argumentées. Leur intérêt est cependant compromis par la fragilité et le caractère artificiel des concepts qu'elles prétendent illustrer, et dont la répétition insistante doit souligner leur convergence et la cohérence thématique de l'ouvrage, mais ne suffit pas à les rendre convaincants. On ne peut définir la notion de "période de transition culturelle » sans passer par celle de « période culturelle », ce qui suppose résolu le très vaste problème de la périodisation historique, et en particulier historico-culturelle et historico-littéraire: la notion de période recouvre-t-elle toujours le même ensemble de phénomènes? Comment définir ses frontières? On peut se demander, dans le cas présent, si ce que l'auteur dit des périodes de transition ne s'applique pas au romantisme lui-même, que l'auteur tente de définir dans son essence comme un système clos de valeurs, mais qu'il paraît plus juste, en tous cas dans le domaine de la littérature russe (ce que du reste l'auteur reconnaît, en qualifiant de "postromantique " l'ensemble du romantisme russe), de considérer dans sa réalité historique comme une période de transition, instable et fluctuante, entre l'époque classique, avec ses "valeurs éternelles » et sa conception rationaliste de l'homme, et les temps modernes, dominés par l'historisme et le goût du divers et du concret.

Le "romantisme ", qui a certes profondément marqué la personnalité de Lermontov et toute sa carrière d'écrivain, où il a trouvé les premiers modèles qui l'ont aidé à découvrir sa propre personnalité, donc, paradoxalement, à s'affranchir progressivement de ces modèles eux-mêmes - le romantisme est le climat littéraire mouvant dans lequel il s'est formé, et non un « dieu » aux traits fixés une fois pour toutes, qu'il aurait consciemment révéré et qui serait resté pour lui une idole.

Il semble bien que le grand défaut de ce livre, malgré l'indéniable finesse de ses observations et de ses analyses, est de substantialiser des abstractions telles que le romantisme et le postromantisme, commodes pour l'historien de la littérature, mais qui risquent de laisser échapper les mécanismes complexes de l'évolution des formes et des sensibilités, et surtout, les ressorts intimes de la formation d'une personnalité unique d'écrivain. 